NOTAS 



\section{NOTAS SOBRE LOS ESTUDIOS LITERARIOS DE PEDRO SALINAS (1930-1940)}

Francisco Abad Nebot

UNED. Madrid

\section{RESUMEN}

Estas Notas analizan -sobre fuentes primarias- los primeros libros o escritos de Pedro Salinas en tanto crítico literario

Palabras Clave: Centro de Estudios Históricos; poesía y realidad; literatura española del siglo $\mathrm{XX}$.

\section{Los cursos de Sevilla y la integración en el Centro de Estudios Históricos}

Pedro Salinas fue el mayor de los del Veintisiete, aunque tuvo una vida corta, parte de la cual transcurrió en un paisaje urbano muy bello: el de la calle de Toledo, calle don Pedro, plazas de la Cebada y de la Paja,... en Madrid (vid. en general para Salinas, Newman, 2004); de sí mismo decía Salinas que era profesor de Historia literaria de oficio y «crítico de afición», pero la verdad es que dio logro a una extensa obra crítico-literaria -más algunas incursiones en el ensayo- que hoy puede visualizarse muy bien en su amplitud: los «Ensayos completos» del madrileño ocupan las 1536 páginas de letra apretada editadas por Enric Bou (Salinas, 2007), y esto -tal como queda apuntado- en muy poco más de sesenta años.

En el curso académico 1918-1919 el catedrático Pedro Salinas se incorpora a la Universidad de Sevilla, y en esa Universidad permanecerá algo más quizá de ocho años, pues no hubo solución de continuidad tajante entre su permanencia en esta Universidad y la incorporación al Centro de Estudios Históricos (vid. Barrera, 1991, y Barrera, 1992, publicaciones necesarias para el asunto).

En Madrid -según queda apuntado- el entonces joven Pedro que se encontraba hacia la mitad de la treintena de su edad, se incorpora al «Centro de Estudios Históricos» de 
la Junta para Ampliación de Estudios, o lo que es lo mismo, entra a formar parte de la escuela filológica de estudios literarios de Ramón Menéndez Pidal; existe una escuela pidalina de estudios lingüísticos bien conocida (cfr. Catalán, 1974), pero hay asimismo otra de estudios literarios: en realidad varios de los miembros de tal escuela cultivaron a la vez lo idiomático y lo literario (desde el propio don Ramón o don Samuel Gili hasta los más jóvenes -con vinculación familiar e individual a Pidal, el mencionado D. Catalán y Álvaro Galmés-), pero algunos otros fueron más decididamente lingüistas o bien estudiosos de las letras artísticas (el propio Salinas es uno de ellos, y en buena medida Dámaso Alonso, quien no se dedicó mucho a la materia oficial de la cátedra que honró sobre un cuarto de siglo -la de filología románica-).

Existe por tanto una escuela pidalina de estudios literarios y de análisis del estilo; entre sus nombres -pero no los únicos- están los del propio don Ramón (épica, historiografía, romancero), más los de Tomás Navarro Tomás (métrica), Américo Castro, Federico de Onís, Homero Serís, Eduardo Martínez Torner, Amado y Dámaso Alonso, Solalinde, Montesinos, Lapesa, Galmés, Catalán, etc.

En la década de los años 20 del siglo pasado en que empezaban a escribir los poetas del 27, Menéndez Pidal avaloraba -desde luego ya desde antes- la forma épico-lírica «romance» y la poesía romanceril toda; don Tomás Navarro -en tanto fonetista de excelencia- empezaba a interesarse sin duda ya por la métrica, y por la representación de las voces de los personajes en las obras literarias, y editaba a Garcilaso; estaban también los intereses folclórico-musicales de Torner; nada digamos del joven Dámaso y de José Fernández Montesinos, quien publicó una antología de la joven lírica y puso en manos de los del 27 el «Cancionero» de Barbieri más la lírica de Lope de Vega; etc.

Realmente el gusto por Garcilaso prendió en el Centro de Estudios Históricos, aunque los estudiosos actuales parecen olvidarlo: publicaciones -antes o después- del aludido Navarro, de Margot Arce, de Pedro Salinas, de Lapesa; incidencia en los textos de Alberti, del mismo Salinas, de Cernuda.

\section{UnA SECCIÓN DE «LiTERATURA CONTEMPORÁNEA» EN EL CEH}

Pero en el presente contexto, debemos detenernos en los años últimos del «Centro de Estudios Históricos» de la Junta, y en la obra hecha allí por Pedro Salinas. Gracias a los trabajos y afanes de esta Junta para Ampliación de Estudios conservamos hoy por ej. la voz de sucesivos literatos en las grabaciones del «Archivo de la palabra»: de los poetas Juan Ramón, Unamuno, y Vicente Medina; de don José Ortega; etc. Por igual dos alumnas sefardíes de la «Residencia de Señoritas» cantaron en este Archivo romances judeoespañoles entre ellos el de Tamar ( $v i d$. desde 1998 una reproducción de las grabaciones del Archivo de la palabra, bajo el título de Voces de la Edad de Plata).

Efectivamente desde finales de 1930, se está formando ya este «Archivo de la Palabra», con el propósito de recoger y conservar en discos de gramófono: «a) La lengua española [...] en su uso corriente y en sus manifestaciones artísticas. b) Idiomas y dialectos hablados en la Península y en los demás países hispánicos [...]. c) Testimonios autofónicos de personalidades ilustres. $d$ ) Canciones, melodías y ritmos populares y tradicionales». La Sección de «Literatura Contemporánea» -nos da también cuenta la Memoria del 
año 32 de la JAE- quedó creada en Marzo de ese año, y ya en Junio empezó a hacer la publicación de «Archivos de Literatura Contemporánea. Indice Literario».

Pedro Salinas da cuenta en Índice Literario de una Antología, la de Poesía española de la Edad Media que hizo don Dámaso; estaban previstos volúmenes que cubrirían toda la posterior secuencia cronológica -hasta el Ochocientos- a cargo de Jorge Guillén, Gerardo Diego y Pedro Salinas respectivamente: sin duda la guerra civil imposibilitó la empresa, aunque el primero de los autores -D. Alonso- reeditó su volumen en Buenos Aires, edición que dejó al cuidado de su amigo fraternal don Amado, y volumen que por fortuna aún se encuentra en librería de viejo (y poseemos).

Se trataba con esta empresa truncada -mantenía don Pedro- de llevar a cabo «una revaloración de nuestro tesoro poético nacional» hasta hacia finales del XIX -hasta el Realismo-, ya que (además) «cada época añade a la historia de los juicios literarios un acento, un tono, una corroboración o una rectificación»: será -añade aún- «lo que una generación literaria española del siglo XX piensa sobre la poesía española de siempre»; tal como vemos, don Pedro identifica ya a su propia generación en cuanto tal, a la que líneas adelante denomina «la generación a la que pertenece Alberti».

Salinas destaca cómo el antólogo persigue más allá de la Edad Media y hasta el Quinientos la serie de la lírica de tipo tradicional, o sea, la de lo medieval que penetra en el «Renacimiento y el Post-renacimiento»; se trata quizá -advertía el comentarista don Pedro- de la parte de la Antología que daría más cosas a conocer al gran público. Desde luego, el volumen de don Dámaso es precioso e iluminador de veras.

\section{UNA CONFERENCIA DESCONOCIDA HASTA I996: «MUNDO REAL Y MUNDO POÉTICO» (I)}

Christopher Maurer ha editado en 1996 -y luego con él, Enric Bou- la conferencia de nuestro autor «Mundo real y mundo poético», que data de 1930; sobre poesía y realidad había discurrido Menéndez Pidal, y lo hará Américo Castro en Tierra Firme: era una temática característica de los filólogos del Centro de Estudios Históricos en el que se encontraba ya don Pedro, y en tal contexto ha de situarse; en cuanto asunto de estética, deberían estudiarse en confrontación las aportaciones que haya sobre esa temática en el seno y en los años del «Centro».

Salinas delimita con nitidez lo que es la serie emocional-intelectual de la poesía de lo que es la serie de los objetos y las cosas, del mundo en un muy amplio sentido de esta voz «mundo», y así dice:

Toda poesía es una posición y una proposición. Se sitúa, propone. Una poesía nos propone algo, nos propone sencillamente otro mundo, otro orbe, ese orbe que ella ha inventado distinto del nuestro. La gran poesía es una proposición de traslado a otro mundo, a un mundo donde los valores corrientes están trastocados, donde las tablas vigentes aquí ya no sirven (Salinas, 2007, p. 378).

Se trata en efecto de que el poeta inventa un orbe, un orbe distinto del de la realidad del mundo. En castellano inventar se remonta a invenire 'hallar', y significa por tanto que el poeta 'encuentra' otro mundo que es el mundo de su ideación emocional y que no se corresponde con la realidad de las cosas: la serie literaria es específica, y justamente es una percepción ingenua la del público que cree que lo referido en un texto lírico, o 
novelesco, etc., se corresponde con lo real; aunque suela decirse que en las letras bellas españolas «Vetusta» es 'Oviedo', no ocurre así, pues «Vetusta» es «Vetusta», no tiene otra realidad que la de pertenecer a un discurso narrativo inmanente -aunque en último término no deja de poseer connotaciones artísticamente secundarias socio-históricas-. En la serie literaria española ya Hernán Pérez de Oliva trazó una Historia de la inuención de las Yndias, la Historia de su hallazgo, de su encuentro o logro.

Hace Pedro Salinas en la charla una referencia al Quinientos poético, y mantiene cómo «nuestra gran poesía se constituye decisivamente en el siglo XVI. En su primera mitad por el miradero de Garcilaso, en la segunda por el de fray Luis de León» (Salinas, 2007 , p. 380). Ciertamente se ha hablado alguna vez de «versificadores» para lo medieval, y de verdaderos poetas ya en el Quinientos, y un compañero de don Pedro en el Centro de Estudios Históricos, Rafael Lapesa, lo apunta entre líneas cuando en la fecha temprana de 1947 muestra cómo «los metros que introducían [Boscán y Garcilaso] eran lentos, reposados, menos pendientes que el octosílabo de la rima acuciadora [, eran de... ] moroso discurrir de endecasílabos y heptasílabos» (Lapesa, 1947, p. 6): estamos así más ante lo verdadero poético que ante una mera versificación. De hecho y en general, se estima -lo hizo al menos una vez el propio don Ramón Menéndez Pidal- que las letras medievales se estudian especializadamente o por obligación escolar, mientras el lector sin más lee sólo desde el Renacimiento, desde precisamente -en el caso de lo españolGarcilaso de la Vega.

La referencia a Garcilaso y a Fray Luis lleva a nuestro autor -a Pedro Salinas- a efectuar un excurso sobre el llamado a veces gran siglo de España, y que en el ambiente del Centro de Estudios Históricos era considerado en cuanto tal. Dicho párrafo enlaza además no sólo con esa avaloración de la centuria, sino con el interés de toda la escuela pidalina de antes de la guerra y luego en años posteriores por la lengua, las letras, etc., del momento -el XVI-, por el Emperador, el Padre Las Casas,..; escribe en particular don Pedro, que es lo que ahora nos importa:

Recordemos todo lo que significa el XVI en la historia de España. Es el siglo del gran dinamismo peninsular, el siglo en que España pone su caudal entero en el tapete de juego. Es el siglo de las pugnas, de los problemas dramáticos. Luchas espirituales, renacimiento y reforma, tradición medieval y paganismo recién brotado, mito contra teología, carne y espíritu. El mundo se moldea y se formula conforme a tipos nuevos. Y nuestro país asume en esta lucha un papel de protagonista; es el actor no de una, sino de varias gestas espléndidas. En el centro de Europa pelea con los príncipes alemanes y con el espíritu de la reforma; en el Mediterráneo con los brotes pujantes del islamismo turco; en América lucha con algo más, lucha con una naturaleza entera e intacta y con un misterio histórico. Todo es pues en España acción, movimiento desatado y caudaloso correr de la vida. A un español del siglo XVI la existencia le ofrece posibilidades de desarrollo vital nunca semejantes (Salinas, 2007, pp. 380-381).

Estamos ante un párrafo de historia cultural -valga decirlo así- que no habría poder salido sino del Centro de Estudios Históricos, en el que desde don Ramón a don Manuel Gómez-Moreno, pasando por sus discípulos, se interesaban por la centuria: Amado Alonso, Federico de Onís, ya está dicho que Navarro, etc.

Ahora Pedro Salinas alude a los problemas religiosos que llenan el siglo -erasmismo, brotes de luteranismo,... entre nosotros-; a la Reforma; al «mito contra teología», hecho muy notorio según a qué mitad de siglo miremos; a España en cuanto «actor pro- 
tagonista de varias gestas espléndidas». Estamos ante la visión retrospectiva de un pasado glorioso de gestas, ante las «ilustres hazañas» que en vez de una «codicia insaciable» proclamaba Menéndez Pidal que movieron a los españoles en la América descubierta en 1492 (Menéndez Pidal, 1957b, 114-126); Salinas así se suma a la historiografía del Centro de Estudios Históricos: nada más lógico o natural que lo hiciese en este 1930. Protestantes y turcos (más franceses, a los que quizá por su galofilia el joven Pedro no menciona) se enfrentan entonces a Carlos y a Felipe, y la Monarquía española «pone su caudal entero en el tapete» -según mostraron bien Ramón Carande y otros historiadores en el orden financiero-, y no sólo el caudal financiero.

Tras el excurso histórico-cultural Salinas concreta qué tratamiento poético da Garcilaso a lo real:

La poesía de Garcilaso [...] es una poesía de nostalgia, poesía de echar de menos, de recordar lo que no se ha vivido, lo que se hubiera querido vivir. El poeta, el cortesano no quiere seguir siendo tales cosas sino que quiere ser pastor, se imagina pastor. Primer grado de desrealización y de distanciación de la realidad. Pero el pastor que quiere ser no es tampoco el pastor verdadero rústico o inculto; es un pastor de invención, de imaginativa, un espíritu sentimental y exquisito. Vemos pues cómo el hombre va huyendo de su personalidad verdadera y se reviste de disfraces. Aquí tenemos ya la palabra que nos expresa uno de los modos que tiene Garcilaso de tratar la realidad. Disfrazarla (Salinas, 2007, p. 381).

Garcilaso no es realista, antes bien encubre lo real con lo literario, tiene el gusto de la idealización, una idealización platonizante según arquetipos de belleza.

Garcilaso -prosigue Pedro Salinas- aleja de su mundo poético todo lo duro, lo común, lo feo, lo vulgar. Y todo eso lo aparta en nombre de un ideal, el de la belleza renacentista, el de la reminiscencia platónica de la belleza ideal de las cosas. [...] Las cosas están como arquetipos de bellezas, no más que nombradas y calificadas en sus adjetivos esenciales (Salinas, 2007, 382).

De manera que en la presente y primera gran lírica española (mantiene y hace síntesis el crítico), encontramos un mundo lírico que no se halla conformado o configurado según resulta la multiplicidad del mundo real (Ibid.). Desde la perspectiva en que se encuentra instalado Salinas - la del tratamiento que da a la realidad el poeta- el otro gran momento del Quinientos surge hacia 1580 con la poesía de Fray Luis, quien halla los cimientos de su mundo lírico «en el menosprecio, es decir en la no valoración de lo que existe en el mundo. [...] Hay que apartarse del mundo, de su ruido, de su barullo. No hay que pensar en las riquezas [...]. No hay que poner en la belleza humana confianza alguna» (Salinas, 2007, pp. 382-383).

Se trata en fray Luis -interpreta el joven Pedro- de abstenciones e inhibiciones que llevan a «un ímpetu, un anhelo característico y definitorio de este poeta, que puede resumirse en una palabra: huir. [...] Instaura fray Luis como móvil de su poesía un ideal. El ideal de escapar, de la fuga, de la huida de este mundo» y hacia el de la bienaventuranza, el de la vida supraterrenal (Ibid.).

Realidad disfrazada y selección según arquetipos constituyen el mundo lírico de Garcilaso; el de fray Luis significa la negación de los valores terrenales y la huida y fuga del mundo real: esta es la interpretación que hace Salinas de los dos líricos; desde luego se trata de apuntaciones que luego y a veces reasumirán algunos críticos (Fernando Lázaro) 
En el Centro la idea que se había formado de Garcilaso y de su tiempo era en efecto la que de manera personal expuso Salinas: en el celebrado artículo de don Ramón aparecido en la revista del momento Cruz y Raya, acerca del lenguaje quinientista, su autor nos habla de tiempos «preñados[s] de hondas inquietudes religiosas en el mundo entero», y apunta cómo ciertamente la poesía se había hallado «privada en el siglo XV de grandes autores nacionales», y que la norma idiomática de Garcilaso -como la de Juan de Valdés- era la de «selección» (Menéndez Pidal, 1933, esp. pp. 356-358).

Otros autores de la escuela pidalina -el mismo don Ramón, y no muchos años más tarde Rafael Lapesa- enunciaron e ilustraron esta misma idea de Salinas de que el poeta de Toledo no poetizaba el natural sino su versión literaria, pues efectivamente en Garcilaso -dicho en palabras pidalinas- «es frecuente [1]a imitación de poetas latinos e italianos» (Menéndez Pidal, 2005, I, p. 830; Lapesa, 1948, passim).

\section{UNA CONFERENCIA DESCONOCIDA HASTA I996: «MUNDO REAL Y MUNDO POÉTICO» (II)}

Va a pasar P. Salinas a hacer algún apunte acerca de la actitud de José de Espronceda ante la realidad, y entonces escribe un nuevo excurso de historia de la cultura en torno al Romanticismo:

Hacia 1830 -son sus palabras- se proclaman [...] los derechos del individuo y del poeta. [...] Para los románticos la sociedad es la ley, la norma, la traba, la limitación. Y se trata de todo lo contrario, de derrocar leyes, de ser no normal, sino anormal, de desprenderse, de ilimitarse. La sociedad es para el romántico lo filisteo, lo burgués, el imbécil mundo burgués. Este hombre terriblemente solo que es el romántico tiene como raíz de su ser psicológico una actitud: la disconformidad. [...] La grandeza del romántico está precisamente en su decisivo ademán insistente de disconformidad. Solo está conforme consigo mismo, con sus ambiciones, con sus pasiones, con sus deseos, con su ilusión. La vida es él; casi todo lo demás son estorbos a su vida (Salinas, 2007, p. 387).

El 1830 aludido por nuestro autor se corresponde efectivamente con los sucesos de Francia y el inicio del verdadero liberalismo político; la fecha equivalente en España es la de 1834 o 1837 y toda la decisiva década subsiguiente, hasta el gobierno de los moderados. Con razón el pensamiento más reaccionario tiene a la década inicial del reinado de Isabel II por una época aciaga del pasado español: es la década en que bajo las sucesivas regencias, se lleva a cabo de manera efectiva la quiebra del Antiguo Régimen, pese a todas sus supervivencias que llegan incluso al mundo académico de nuestros días.

Sin embargo no cabe coincidir en todo con el perfil de la psicología del romántico trazada por nuestro crítico: lo de que la vida es él y lo demás resulta un estorbo para esa vida, debe predicarse asimismo de quienes poseen trastorno narcisista de la personalidad: el romántico es emocional, y puede incluso resultar narcisista, mas es un narcisista emotivo y primario; quien lleva en sí un trastorno narcisista de su personalidad es emotivo pero no primario, sino -en la misma terminología técnica- «idiota moral» y secundario, fríamente consciente. Por sentimental, el romántico no puede caer en lo que los filósofos denominan la idiotez moral.

Salinas proclama cómo Espronceda es «el más grande lírico español del romanticismo» (Ibid.), y cita literalmente al poeta y lo glosa: 


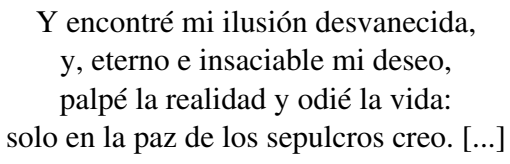

Pero en cuanto [el romántico palpa el mundo real] -«palpé la realidad»- se convence de que le han engañado. No, eso no es lo que él quería. Él se figuraba que aquello era otra cosa. Y se llama a engaño con la frase terrible y tremebunda: odié la vida. En suma, para el romántico el mundo real es por un instante bello, atractivo, prometedor. Es una ilusión. Pero luego se descubre en seguida la verdad: la realidad, el mundo real es un fracaso, un irremediable fracaso. Y la insulta, la odia, la escarnece. [...] Hemos llegado al punto máximo de encono y diferencia entre mundo real y mundo poético [..:] el poeta niega, odia, insulta a la realidad (Salinas, 2007, pp. 388-389)

Y entonces zarpan las naves con las velas hinchadas de lirismo -prosigue y estampa el asimismo escritor Pedro Salinas- hacia el nuevo continente, el mundo interior cuyas pequeñeces hacen su grandeza. Y los románticos llegan en su odio a la vida prosaica, al mundo material, a intentar matarlo. [... Esos románticos] no son suicidas. En verdad [... eran] mundicidas (Ibid., p. 389).

La actitud del romántico ante la realidad la sintetiza en su límite nuestro crítico en los sentimientos de fracaso y de anhelo de -dicho con un «feo neologismo»- ímpetu de mundicidio.

Un autor algo más joven de los del 27, uno de los que Rafael Lapesa llamaba «hermanos menores» del Veintisiete -nos referimos a Jaume Vicens- caracterizó el Romanticismo de manera que incide ya en rasgos que vienen a coincidir con las estimaciones de Salinas, a saber:

Como movimiento cultural, el Romanticismo se propuso la rehabilitación del espíritu y el genio de las naciones, revelado en sus costumbres y tradiciones (folklore), en su arte, en su derecho e instituciones propias y, sobre todo, en su lengua (y de aquí los numerosos renacimientos en las literaturas europeas) [... El Romanticismo] preconizó la autonomía artística, el desprecio de toda norma, la manifestación del yo personal, la satisfacción de lo apasionado y vital. Lo primitivo, lo bárbaro, lo sanguinario; el conquistador, el pirata y el bandolero fueron temas constantes en la musa y la paleta de los románticos» (Vicens, 1945/1960, pp. 470-471).

De su lado otro autor a veces bien agudo y poco más joven que los del Veintisiete, José Luis López Aranguren, ha incidido también en un bello libro y a su manera, en algo de lo interpretado por Salinas, aunque de manera independiente. El odio romántico al mundo consiste en efecto -apunta Aranguren en un párrafo que no debe quedar inadvertido- en un rompimiento con ese mundo:

Para los románticos la felicidad es por esencia una aspiración infinita e irrealizable, trascendente al mundo, más aún, en abierta ruptura con él. Sólo una «eticidad ingenua», antigua, infantil, ha podido sentir el mundo [-según la percepción romántica-] como hogar de paz y bendición.

La expresión «conciencia desgraciada» (acuñada, como se sabe, por Hegel), que recubre muchas formas históricas de vida, pero cuyo modelo más próximo fue para él indudablemente el romanticismo, define bien, en presencia de ese mundo injusto y mediocre, obstáculo infranqueable a la realización de los más altos anhelos del corazón, este sentido de fracaso de la existencia en cuanto tal por una mutilación que le es, por constitutiva, insuperable. Es 
el sentimiento de la vida como «destierro», y más aún como tragedia y agonía. El drama trágico, por ejemplo Don Álvaro o la fuerza del sino, en el que la libertad se estrella contra el fatalismo del destino, casi todo el teatro romántico español, y la poesía de Espronceda, así como el intimismo posterior de Bécquer, dan palabras y versos a este sentimiento de fracaso existencial cuya única salida [...] es en fin de cuentas la poesía, el refugio en el ensueño, en el recuerdo personal o en la memoria histórica idealizados (López Aranguren, 1970, p. 79).

De manera que resulta pertinente trae a colación Aranguren el concepto de «conciencia desgraciada»: ante la realidad -nos ha dicho Pedro Salinas- pasa el romántico de la ilusión al fracaso, y ciertamente la conciencia desgraciada o infeliz -recuerda otro «hermano menor» del 27, José Ferrater Mora- «es «el alma alienada ['enajenada'] que es la conciencia de sí como dividida, un ser doblado y meramente contradictorio»» (Ferrater, 1979, I, vol. p. 563b). Estas palabras ilustran bien lo que el poeta y crítico madrileño nos traza como etopeya de los románticos y de José de Espronceda.

Los anhelos del corazón ciertamente se ven impedidos por un mundo real que los escritores del Romanticismo detestan con aborrecimiento. Y en lo que Pedro Salinas denomina sensación e ímpetu vital de «mundicidio», símbolos de esa lucha resultan -según es sabido-, el bandido, el pirata, el reo de muerte, el verdugo,..., y con esto la moral romántica hace una denuncia social hacia la buena conciencia de las gentes conservadoras que el propio José Luis Aranguren interpreta de esta manera que debemos recoger: «La sociedad lava sus culpas haciendo una víctima propiciatoria [el reo de muerte], ejecutada por el verdugo, que a su vez es proscrito por la sociedad y por tanto convertido en víctima propiciatoria también. La denuncia -justa- de este reparto de papeles, cómodo para la buena conciencia de la sociedad [para la necesidad de la «buena conciencia» social], que no se siente así ni criminal no verdugo, [...] es una de las grandes denuncias de la moral romántica» (López Aranguren, 1970, p. 81).

De otra parte José Moreno Villa, a quien podemos tener por un «hermano mayor» de los del 27 -era nada más que cuatro años mayor que Salinas-, y que en la vida de la Residencia de Estudiantes y en la vida madrileña ejerció en verdad de un hermano mayor de la generación, Moreno Villa (decimos) había apuntado asimismo lo que poco más tarde sugirió Salinas -ambos eran colegas del Centro de Estudios Históricos-; editó y prologó a Espronceda, y señaló en lo que llamaba su ideología que

el individuo era un fin por sí mismo: él hace y deshace, crea y destruye. Lo que importa no es la ley o conducta moral, sino la conducta artística; que la vida y la obra estén henchidas de personalidad creadora, de genio. De aquí que los románticos no vieran la grandeza humana en lo común que nos une, sino en lo diferencial que nos aísla, nos levanta o nos hunde. Comulgan [...] en el yo de Fitche. Tienden a sobresalir del vulgo; odian el filisteísmo prosaico; hablan a cada paso de «una vida más elevada», «un pensar más digno y levantado». La norma era huir de lo trivial y lanzarse a regiones abstractas o inefables» (Moreno Villa, 1976, pp. 244-245).

Sin necesidad de hacer apelación a lo que pedante y un tanto innecesariamente los semiotistas denominan «intertextualidad», resulta creemos que evidente cómo en la conferencia de Pedro Salinas se halla presente una reminiscencia de la memoria del poeta respecto del texto no muchos años anterior de José Moreno Villa: una caracterización del Romanticismo con puntos de analogía salió del Centro de Estudios Históricos 
En fin llega Pedro Salinas en esta revisión de las actitudes de los poetas ante la realidad, a los propios días en que él ha vivido, y en que una parte de nuestros contemporáneos ha empezado a vivir. Estamos ya en las décadas iniciales de la centuria del XX, las de la primera vanguardia artística, y advierte el escritor madrileño:

La presión que hoy ejerce la realidad, el mundo real, lo que nos rodea, sobre el espíritu del hombre es mayor que nunca. Ese mundo de la realidad ha logrado una ampliación extraordinaria. [...] La cantidad de objetos bellos creados por el hombre de hoy y que este encuentra a su alrededor donde quiera que ponga los ojos[,] no tiene comparación con el repertorio de la vida material de ninguna época. [...] Paralelamente el concepto de belleza sufre también una ampliación enorme. Una gran cantidad de cosas que siempre estuvieron excluidas de esa consideración, un hipopótamo, una bailarina negra, una fila de cacharros de aluminio, presentan hoy su instancia a ser reconocidos como bellos. Hay una verdadera rebusca, una ardorosa y frenética persecución de bellezas inéditas. [...] Piénsese en la fuerza gigantesca, en el poder sin límites que tiene el mundo real en nuestros días (Salinas, 2007, pp. 391-392).

Con sus palabras, al decir que ya en los días de las décadas primeras del Novecientos se da «una verdadera rebusca, una ardorosa y frenética persecución de bellezas inéditas», Pedro Salinas nos está definiendo qué es una actitud vanguardista, nos remite a uno de los caracteres del espíritu de vanguardia.

Cabe recordar ahora el poema de don Pedro «Navacerrada, abril», en el que se hace un canto al automóvil -está en Seguro azar-:

Los dos solos. ¡Qué bien
aquí, en el puerto, altos!
[...] Alma mía en la tuya
mecánica; mi fuerza,
bien medida, la tuya,
justa: doce caballos.

El poeta madrileño acaba esta conferencia ahora conocida «Mundo real y mundo poético», con la proclama de lo que ocurre artísticamente en sus días: «Es por consiguiente imposible -manifiesta-, totalmente imposible, que todas estas inmensas presiones [de la realidad tan «multilateral», del mundo real] dejen de actuar agobiadoramente sobre la poesía de hoy» (Salinas, 2007, 393); matiza y particulariza no obstante cómo la poesía pura defiende la existencia de una realidad misteriosa ['sentimental, idealizada, que se halla en la conciencia del poeta o el lector'], y no real; cómo los creacionistas niegan la realidad elemental; o cómo el superrealismo rechaza la realidad en cuanto se halla ordenada con lógica (Salinas, 2007, 393-394).

Aunque Salinas llegará a ser muy consciente de los males y desgarros deshumanizadores que han traído el maquinismo y el progreso de la tecnología, ya vemos que a sus cuarenta años se muestra como en realidad todo el Veintisiete lírico, esto es, con un sentido de la vida alegre, amistoso, libre, de libertad sexual, etc.

\section{LAS CONFERENCIAS TURNBULl EN CASTELLANO (I976): «LA REALIDAD Y EL POETA» (I)}

El asunto de la poesía y la realidad reaparecerá enseguida de la conferencia del año treinta «Mundo real y mundo poético», y será en el subsiguiente 1937, en la serie de 
conferencias de ese año pronunciadas en la cátedra Turnbull de poesía, cuyo texto en castellano no se ha dado a conocer sino en 1976.

Cabe revisar esas lecciones, en un momento de las cuales don Pedro llama a Menéndez Pidal «mi querido maestro»: estamos ante el Salinas que lleva en sí el Centro de Estudios Históricos y lo evoca sin duda ya desde el exilio con tristeza interior.

La actitud del poeta ante la realidad que prevalece en los poetas primitivos es la de reproducirla -plantea Pedro Salinas-. El poeta, de manera elemental, lo que hace ante tal realidad es «examinarla, tomar nota de ella, contarla. Esto es lo que hace la épica, que observa la vida en movimiento, lo que pasó, y nos da pura y simplemente el resultado de esa observación» (Salinas, 2007, p. 411). Nos hallamos por tanto ante «la reproducción de la realidad»; de acuerdo en efecto con el maestro Menéndez Pidal, Salinas anota que «nuestros primeros poetas no interpretan, ni preguntan, ni idealizan: se limitan simplemente a contar. Cuentan las realidades históricas más cercanas a ellos. [...] El distintivo esencial de la poesía heroica española es su exactitud histórica», por lo que «la primera actitud del poeta español ante la realidad [...] se manifiesta en el poema épico narrativo».

Desarrolla además cómo «las otras realidades, la de la vida interior, el mundo sentimental, la experiencia religiosa, en suma la vida no heroica, apenas existen como materia poética, y si aparecen, es en forma narrativa; lo mismo ocurre en el caso de los poemas religiosos» (Ibid.; sobre los aludidos textos no heroicos, vid. Menéndez Pidal, 1957 a, esp. «Parte tercera: Los juglares de poesía narrativa» -páginas que en una versión anterior conoció Salinas-; Menéndez Pidal 2005, I, pp. 437-506 y otras).

De acuerdo con don Ramón, el autor madrileño expone que ciertamente «nuestro héroe nacional, Rodrigo Díaz de Vivar, el Cid, es un hombre de carne y hueso cuyos hechos conocemos con relativa exactitud histórica» (Salinas, 2007, p. 412): estamos de esta manera ante una «biografía poética».

Don Pedro hace además una bella observación estilística, dirección de análisis estilístico que él comparte con otros compañeros del «Centro de Estudios Históricos» (el mismo Menéndez Pidal, los dos Alonso, etc.):

El poeta [de «Mio Cid»] crea la primera metáfora de la poesía castellana. Escribe (v. 375): Assis parten unos d'otros commo la uña de la carne.

Esta es la primera flor de la lengua poética castellana. El primer esfuerzo por decir las cosas de otra manera, por buscar en la lengua los oscuros senderos que llevan a la luz de la poesía. Una metáfora brutal, dura, violenta. Una comparación entre el sufrimiento del alma y un agudo dolor físico. [...] Expresado en palabras tan faltas de idealización, tan completamente antiestéticas y llenas de objetividad humana (Salinas, 2007, p. 414).

Nuestro autor entiende además que en la exclamación del Poema «Dios, qué fermoso apuntava» se encuentra en germen «el paso de la naturaleza percibida a la naturaleza sentida» (Ibid., p. 415), o dicho por nosotros en otras palabras, el paso del tema del paisaje a la expresión del sentimiento de la Naturaleza.

¿Cuál es entonces -quiere sintetizar Salinas- la actitud ante la realidad que se da primero en la poesía española?: «la percepción directa y fiel reproducción. Es la percepción reproductiva. [...] No altera nada el poeta», de tal manera que con este Poema de Mio Cid se manifiesta «la actitud poética «primitiva» de asombro ante el mundo y el deseo de reproducirlo» (Salinas, 2007, p. 419). 
Nuestro crítico alude por igual al romancero y a algún romance en concreto -«Álora, la bien cercada», en que queda incorporado al poema «todo lo que el ojo puede ver»-, y concluye de la misma manera que con el «Cid»: en el discurso romanceril «la realidad es un valor absoluto. [...] Poetizar es reproducir» (Ibid., pp. 421-423).

Pedro Salinas había hecho una versión moderna del Poema de Mío Cid (1926), y lo interpretará literariamente en varios escritos; estamos ante una huella pidalina en él. Tal versión en metro romance de este Poema llevó una dedicatoria: «A Don Ramón Menéndez Pidal, Cid de lo cidiano, su amigo y discípulo Pedro Salinas», y en su «Prólogo», Salinas hacía notar cómo el texto entonces creído de hacia 1140 -ahora se le tiene por de hacia 1200-, «ha logrado lectura y admiración universales gracias a los espléndidos estudios y ediciones de don Ramón Menéndez Pidal» (Poema, 1975, p. 11).

El autor madrileño subraya también cómo además de los valores para la ciencia linguística y para la historiografía de un texto del siglo XII (del XIII quizá), «puede haber, y ese es el caso del Poema de Mío Cid, un valor literario sustantivo y permanente», y apostilla: «Nuestro Cantar, por rico que sea para la Filología y la Historia, lo es todavía más para la poesía española» (Ibid.); Pedro Salinas se está manifestando así con una visión inmanente y artística de la serie literaria, pues avalora el Poema por su textura en tanto obra literaria: es la visión no tanto filológica como la de don Ramón, sino formalista -en el sentido amplio de la palabra- caracterizadora de los autores del Veintisiete. Notemos asimismo que el crítico habla de «nuestro Cantar» seguramente como una variante estilística, para no repetir tantas veces la voz «Poema», ya que realmente se trata de un poema en tres cantares.

En fin el entonces treintañero don Pedro desea con la versión que hace en lengua castellana del siglo XX, bastantes centurias posterior a la del texto original, «la conquista, que ahora pueda realizar [el Poema], de gustos y sensibilidades antes inaccesibles» (Ibid., 12). Dámaso Alonso reseñó en el tomo XIII de la Revista de Filología Española la presente versión hecha por Pedro Salinas, y se pronunciaba con estas palabras: «Estamos de enhorabuena. En P. S., el hombre de ciencia ha colaborado con el agudo poeta moderno. El viejo Poema no ha sido profanado ni traicionado».

Volvemos al tratamiento de la realidad en la poesía española, y si para nuestro crítico este «Poema de Mío Cid» así como en general distintos romances lo que hacen es reproducir la realidad, otros poetas «aceptan» la realidad. Jorge Manrique compuso sin lugar a duda «la mejor elegía lírica de nuestra literatura» (Salinas, 2007, p. 427) -mejor, parece decirnos el crítico, que el Llanto lorquino por Sánchez Mejías, que algunos estudiosos parangonan en calidad-.

Y desde el punto de vista analítico en que se halla instalado el madrileño, va exponiendo:

Esta es la última conclusión [de Jorge Manrique]: no debemos dejarnos confundir por la realidad engañadora o aparente, sino hacer buen uso de ella. No debemos desdeñarla porque en ella se dé la falsedad, sino vivirla valientemente, hacer buen uso de las apariencias, porque al final nos espera la vida eterna, la salvación. Es el poema más puro sobre la dignidad de la vida. Es la concepción de la vida de un caballero cristiano (Salinas, 2007, p. 434).

Nos encontramos entonces -interpreta nuestro crítico- con que se trata de vivir y ser en conformidad con lo real, en aceptar el paso de la vida plenamente: «Solo el que acepta 
[... la muerte...] está de acuerdo con la vida, [... ha] aceptado la vida en su más aterradora dimensión, la de ser un don transitorio y sobremanera perecedero» (Ibid). Diez años más tarde -y según es sabido- Salinas dedicará una monografía entera a Jorge Manrique, a la que habremos de aludir.

Para él (para Salinas) igual temática e idéntica solución que el poeta medieval, de aceptación de la realidad, presenta don Pedro Calderón en La vida es sueño. A manera un tanto de excurso, ha escrito Salinas en el capítulo que vemos ahora de su libro, unas percepciones muy brillantes acerca de lo que de manera más tosca a nosotros $-\mathrm{y}$ de seguro que a otros lectores más- nos había llamado la atención hace tiempo: lo que expresa acerca del nacer como delito y de la existencia humana un autor consagrado a Dios como Calderón. Escribe ciertamente P. Salinas en unas líneas como decimos muy brillantes

Por boca de Segismundo habla el hombre maltratado de todos los tiempos [«pues el delito mayor / del hombre es haber nacido»], todos los hombres a quienes se les ha dado vida sin libertad, todos los que han sido encadenados por la sociedad. En Segismundo hablan las víctimas de la injusticia. Y es muy curioso observar cómo en plena monarquía católica española, la monarquía más aristocrática y absoluta de aquella época, un poeta católico y monárquico hace que uno de sus personajes pronuncie una de las más violentas y persuasivas defensas [...] de la libertad [ «¿y teniendo yo más alma, / tengo menos libertad?»]. Al defenderse Segismundo como hijo tiranizado por su padre, está defendiendo los derechos naturales del hombre (Salinas, 2007, p. 437).

El crítico madrileño deseaba y casi pedía que con su versión modernizada en verso del «Cid» ese texto llegase a más gentes y despertase su sensibilidad; como mero lector creemos que pasajes como el presente invitan de manera poco resistible a leer o leer de nuevo asimismo La vida es sueño. ¡Qué gran crítico -debemos exclamar y permítasenos decir- fue Pedro Salinas en una vida tan fugaz!

Y para ilustrar derechamente la actitud de conformidad ante lo real de Calderón, Salinas escribe esta vez: «El despertar es la muerte», y menciona más tarde los versos calderonianos «¿quién por vanagloria humana / pierde una divina gloria», para interpretar en esencia:

¿Cómo olvidar la gloria divina por esta gloria humana que quizá no sea más que un sueño? [...] La vida se acepta con honor y dignidad. [...] Es heroico el aceptar [la vida como Calderón], sabiendo que quizá no sea más que un sueño. [...] Solo acepta la vida heroicamente el que se atreve a todo como Segismundo, el que actúa a pesar de la duda y la sospecha de que solo sea sueño (Salinas, 2007, p. 440).

En síntesis, Jorge Manrique y don Pedro Calderón mantienen ante la realidad en su literatura la idea de aceptación de la realidad «con todos sus riesgos», interpreta el crítico (Ibid., p. 441).

La «idealización» de la realidad la percibe e interpreta P. Salinas en Garcilaso, a quien vuelve ahora otra vez. Habla ya en este 1937 de una «revolución» que haría inflexionar el curso de la poesía española: estamos ante el hecho -nos advierte- de que

muchos piensan que consiste, sin más, en la adopción dentro de la lírica española del verso endecasílabo en sus varias combinaciones estróficas. Hasta entonces el verso utilizado en castellano era el octosilábico, el del romance. Pero la gran transformación de nuestra lírica [... supuso por igual que la poesía castellana] asimiló mucho más [que las formas métricas]: 
el vasto contenido de sensibilidad y visión poética que se había ido formando en Italia desde Petrarca hasta el siglo XVI (Salinas, 2007, p. 443).

Estéticamente se trata de una revolución en las formas inmanentes de expresión, en este caso en las formas métricas, y de revolución en los contenidos. Así debía pensarse en el Centro de Estudios Históricoa, pues Lapesa, en su aludida antología de poetas del XVI, dirá tempranamente: «El moroso discurrir de endecasílabos y heptasílabos [...] era el ritmo adecuado para la exploración del propio yo en detenidos análisis y para expresar el arrobo contemplativo ante la naturaleza. Estos eran los dos grandes temas de la nueva escuela. Petrarca, «el primer hombre moderno», había dado la pauta para el escrutinio del interior anímico [...]. Y los poetas, al explorar así el propio espíritu, cobraban conciencia de sí mismos y contribuían al descubrimiento del individuo, hecho capital del Renacimiento» (Lapesa, 1947, p. 6, palabras e ideas repetidas luego en Lapesa -1962-, incorporado a Lapesa, 1967, pp. 145-171).

Lleva a cabo Pedro Salinas -como sabemos que ha hecho con el Romanticismo, con las décadas primeras del siglo XX-, una caracterización de la cultura del Renacimiento, y establece entonces, en líneas y párrafos que no deben quedar inadvertidos del presente libro suyo también un tanto inadvertido:

Los hombres del Renacimiento hacen una apología de la naturaleza y de las fuerzas naturales, y crean lo que equivale a una religión de lo natural.. [...] La naturaleza viene a ser una especie de agente de Dios. [...] Encontramos así en el alma renacentista una permanente tendencia positiva hacia lo natural, hacia la naturaleza como fuente del bien y de la perfección. Es la tendencia naturalista del período [...]. Pero esa fuerza se encuentra y se confronta con otra que se le opone: el idealismo, el culto a las ideas como la suprema expresión de la dignidad humana, el cultivo de lo intelectual en el hombre, su capacidad de conocimiento y de abstracción. El Renacimiento es esencialmente cultivo del hombre, cultura, concentración en las facultades de la mente humana. Por otra parte, es la observación de los fenómenos naturales, de los animales y las plantas (Salinas, 2007, pp. 449-450).

De esta manera ocurre que la temática pastoril o idealista resulta de la armonización (de la paz o tregua, dice a la letra nuestro autor) entre el impulso del Renacimiento realista-naturalista, y su impulso intelectual-espiritual (Ibid.).

Algo de estas percepciones de Salinas le vienen del Centro de Estudios Históricos y él las comparte, desarrolla, reexpone, etc.; en particular Salinas podía remitirse para la cuestión de qué caracteriza al Renacimiento al volumen de Américo Castro El pensamiento de Cervantes, y en concreto a su capítulo IV, a saber: «La Naturaleza como principio divino e inmanente» (Castro, 1925, pp. 156-209); el mejor Américo Castro -que en varios aspectos intelectuales creemos que es el de entonces- estampó por ej. unas líneas que parecen hacerse presentes en lo dicho por don Pedro y que queda visto poco antes: «El siglo XVI -manifestaba Castro-, llevado por estímulos emocionales, buscará afanoso la virtud natural donde piensa que se halla [...]. Pero al mismo tiempo el Renacimiento busca con no menor afán la cultura, que es razón, y que es lo contrario de la espontaneidad natural» (Loc. cit., p. 181).

Persona no lejana a Ortega y Gasset y a Menéndez Pidal fue el estudioso de la historia de nuestro pensamiento político y de nuestra historia de la cultura y de la literatura José Antonio Maravall -internacionalmente se tiene a su libro sobre la picaresca 
como una aportación de relieve, aunque fuese elaborado hace unos treinta años y no pudiese conocer indagaciones posteriores-; este autor inmediatamente posterior al 27 , poeta él mismo en su juventud y amigo de Leopoldo Panero, tiene un volumen rotulado «Estudios de Historia del pensamiento español. Segunda serie. La época del Renacimiento», pero que bien podría haberse denominado *La cultura del Renacimiento, y que pese a su proximidad informal al «Centro» tiene un concepto del Renacimiento tanto español como europeo bastante distinto ya del que pudieron sostener Américo Castro y Pedro Salinas.

No podemos hablar aquí de «intertextualidad»-valga en este momento la palabraentre Salinas y (Américo Castro y) José Antonio Maravall, pese a la amistad personal entre los tres y a los contactos vitales que sabemos que tuvieron, y esto ocurre dada la marcha de nuestra historiografía general. La historiografía del Centro de Estudios Históricos poseía el mejor positivismo documental en los datos, y además un enfoque romántico (tanto don Ramón como A. Castro y Claudio Sánchez Albornoz operan con las ideas románticas de espíritu de los pueblos o caracteres nacionales; con la de los héroes -el Cid; los conquistadores de América de hazañas increíbles-; etc.). Pasados los años, J. A. Maravall se hará un historiador no sólo de las ideas, sino de las estructuras particulares y situacionales de lo histórico, que comportan estados de estratificación social, mentalidades, economías,... Aunque resulte casi anecdótico, no deja de resultar revelador que en el volumen mencionado este autor escriba que «históricamente no es menos significativo que la invención del endecasílabo la del endoso de la letra de cambio» (Maravall, 1984, p. 42). La historiografía se ha transformado, y el Renacimiento no se ve ya sólo como lo hacía Salinas (sobre el concepto fundamental de estructuras de lo histórico -Renacimiento, Barroco, era de la violencia, etc.,- vid. Maravall, 1967).

Volvemos a las páginas del libro de don Pedro «La realidad y el poeta», y cabe señalar cómo en relación más en particular ahora al escritor Garcilaso de la Vega, Salinas hará afirmaciones como estas:

a) «Los versos del nuevo estilo que introduce, las estrofas empleadas por vez primera, fueron adoptados para siempre por los poetas del Siglo de Oro español. [...] A ningún poeta debe más la poesía de lengua española que a Garcilaso» (Salinas, 2007, p. 448).

b) «Garcilaso fue el mayor escritor de poemas líricos de la España de su tiempo, y quizá lo sea de la España de todos los tiempos con excepción de Bécquer» (Ibid., p. 451). Digamos y recordemos cómo Bécquer se halla muy presente en el 27.

$\mathrm{Y}$ en cuanto a la actitud del poeta ante la realidad, nuestro crítico analiza el soneto $\mathrm{V}$ del toledano («Escrito está en mi alma vuestro gesto, / y cuanto yo...»), lo parafrasea, y comenta en lo que le resulta más pertinente:

No es desde luego Garcilaso el primer poeta en decirnos que vive por el amor y que amará hasta la muerte. Muchos lo habían dicho en el curso del siglo XV. [...] La convención y la fórmula atenuaban hasta tal punto su afirmación de amor que casi nunca nos sentimos tentados de tomarles en serio. Pero en este soneto de Garcilaso el amor irrumpe con una especie de ardor persuasivo que nos convence de su existencia real [...]. Lo otro era un juego; aquí el amor surge implacable, en toda su seriedad (Ibid., p. 452). 
Y Pedro Salinas alcanza dos conclusiones: a) que la lírica amorosa castellana empieza en este soneto $\mathrm{V}$, y que lo anterior debemos tenerlo por prehistoria; y $b$ ) que en el proceder de Garcilaso «la vida, realidad impura, se convierte en pura poesía» (Ibid., pp. 452 y 457).

Aunque sea de manera informal e intuitiva, contrástese la diferencia a favor de Garcilaso que hay entre su lírica amorosa, y por ej. este texto anterior de Juan de Mena:

$$
\begin{gathered}
\text { Más clara que non la luna } \\
\text { sola una } \\
\text { en el mundo vos naçistes, } \\
\text { tan gentil que non ovistes } \\
\text { nin tovistes } \\
\text { competidora ninguna. } \\
\text { Desde niñez en la cuna } \\
\text { cobrastes fama e beldad, } \\
\text { con mucha graçiosidad } \\
\text { que vos dotó la fortuna } \\
{[. . .]}
\end{gathered}
$$

Otro capítulo de La realidad y el poeta se halla dedicado a Fray Luis de León y San Juan de la Cruz, a «la evasión de la realidad», a la huída de lo real.

Salinas transcribe por ej. los versos de fray Luis

$$
\text { el trabajo perdido, }
$$

la falsa paz, el mal no merecido,

y los tiene por versos confesionales, confidenciales, sin disimulos.

«El «trabajo perdido»-glosa P. Salinas- quiere decir que fray Luis, gran trabajador, incansable estudioso, acaba por creer que su esfuerzo es inútil. La «falsa paz» significa que el reposo que encontramos aquí es realmente solo aparente, erróneo. El «mal no merecido» son las injusticias, las heridas infligidas a su alma honorable por la estupidez y las malas pasiones de los hombres» (P. Salinas, 2007, p. 464).

Fray Luis -esta es la postura del poeta ante la realidad- no huye para no experimentar más sufrimiento -que podría ocurrir-, sino en la interpretación del madrileño, por algo de más sustancial calado, «por la incompatibilidad de su alma con este mundo», pues ve cuanto le rodea «como repugnante», y huye «hacia algo» (Salinas, 2007, p. 465).

La huida luisiana es búsqueda -entiende en definitiva el crítico-,

y dos personas se evaden en esta huida: una el hombre sensible herido, el cristiano que sufre por las miserias del mundo [...]. Pero la otra es el espíritu que ansiosamente busca entender la esfera terrestre. El primero huye de la realidad de la envidia, del mal, del sufrimiento; el segundo de la confusión, del error, de la oscuridad.[...] La huida [...] de los sentidos y de la inteligencia, maravillosa fusión en este poeta de los dos ideales del siglo XVI» (Salinas, 2007, p. 468).

El poco más joven que los del 27 Emilio Orozco, enfocó a Fay Luis de una manera algo distinta y con otra complejidad, debida en este caso a la formación en otras artes del crítico y acaso asimismo a la creencia religiosa más intensa que la de Salinas que poseyó este granadino. Orozco ha escrito por su cuenta -verosímilmente no conoció las páginas del madrileño- algo emparentado con lo que hemos visto en don Pedro: cómo «fray Luis 
es el auténtico intelectual de temprana y firme vocación religiosa, que vive ascéticamente como sabio y poeta cristiano en perpetua nostalgia de la verdadera paz y la verdadera ciencia del otro mundo» (Orozco, 2004, p. 92; hemos subrayado nosotros).

Anhelo de paz y anhelo de saber caracterizan al agustino (Salinas, Orozco), como lo caracteriza su cristocentrismo (Dámaso Alonso, Orozco); el mismo Emilio Orozco desarrolla inteligentemente por igual cómo de esta manera -tras saber lo anterior-, «comprendemos así por qué en sus poesías originales sobre los temas del apartamiento, de la huida de todo lo mundanal, de la soledad, del gusto por la naturaleza tranquila [...,] emergen estos dos temas de la noche serena y de la música, que se unen [...] como cima de su pensamiento y de su vida espiritual» (Orozco, 2004, p. 304).

El poeta Fray Luis hace en su obra lírica una evasión de lo real, y de igual manera escribe -en la interpretación de Pedro Salinas-San Juan de la Cruz; a ambos -Fray Luis, San Juan- los tiene el madrileño por «los dos más grandes poetas místicos de España» (Salinas, 2007, p. 475), estimación a la que no llega el mismo Emilio Orozco, para quien el agustino no llegó a alcanzar el grado espiritual del misticismo.

De la evasión de lo real llevada a cabo por San Juan, escribe en esencia P. Salinas que el carmelita «huye hacia dentro de su alma» (Salinas, 2007, p. 464).

Diferente actitud ante la realidad nos muestra el crítico madrileño que es la gongorina, pues el lírico «exalta» lo real, esa realidad varia, contrastada y compleja que en cuanto contenido temático caracteriza al Barroco.

Pedro Salinas -fiel en esto a su maestro don Ramón Menéndez Pidal- distingue implícitamente dos siglos de oro, el XVI y el XVII, pues percibe otras tantas «revoluciones poéticas» entre nosotros; Pidal era muy escrupuloso analíticamente, y de esta manera delimitó ya en fecha relativamente temprana una centuria del Quinientos (cfr. en este sentido Manéndez Pidal, 1933), y otra del Seiscientos, de ideales lingüístico-estilísticos diferenciados.

En correspondencia con tal diferenciación analítica, Salinas establece -ya que es el único crítico (de entre los que recordamos) que lo hace de modo expreso-, cómo «la poesía de tipo italiano [... introducida por Garcilaso] reinó por muchos años y fue la única escuela poética española. Pero a comienzos del siglo XVII ocurre en nuestra historia literaria un hecho que equivale a una nueva revolución poética y que altera el curso [...] de nuestra lírica»: se trata de la «publicación» de las «Soledades» y la «Fábula de Polifemo y Galatea» gongorinas (Salinas, 2007, p. 477; el vocablo «publicación» ha de entenderse en el sentido amplio de 'difundir un escrito', no en el sentido más usual y actual de la palabra). Y desarrolla el madrileño una etopeya literaria del cordobés: «Góngora es el tipo perfecto de artista disidente, excepcional, que despierta con su obra las mayores antipatías y las más ardientes admiraciones, es el sembrador de discusiones y polémicas, el verdadero agitador de toda una época» (Ibid.); estamos ante una cuestión -dice el crítico en estas páginas suyas de 1937- «que hoy sigue viva» (otra etopeya -esta vez psicológica- de Luis de Góngora trazó Fernando Lázaro Carreter, un tanto metodológicamente en contradicción con las posturas crítico-formalistas estrictas que en otros momentos sostuvo).

La polémica sobre don Luis y el gongorismo o culteranismo -advierte Salinas con acierto- es el hecho más saliente en la historia de las doctrinas literarias» del XVII español (Salinas, 2007, p. 480). Y para Salinas (luego para Emilio Orozco, etc.), la «obra 
esencial» de don Luis fue la de las «Soledades» (Salinas, Ibid.), estimación en que los acompañamos, aunque don Dámaso hiciera énfasis sobre la dificultad y el logro estético del «Polifemo».

Yendo a la temática específica de la realidad y el poeta y en referencia a don Luis, establece nuestro crítico don Pedro:

En la base del concepto poético de Góngora parece haber un principio: [...] la insuficiencia poética de la realidad. La realidad cruda, pura, no es suficientemente poética. [... ¿Qué habrá que hacer para convertir la realidad] en poesía? Realzarla, acentuar extremadamente sus caracteres, elevarla por encima de sus formas naturales, extrayendo de ellas todas las capacidades estéticas de que sea capaz la imaginación y la fantasía. Hay que transformar la realidad, transmutarla a otro tipo de realidad poética, material, sonora, plástica (Salinas, 2007, p. 482).

Se trata pues de realzar lo real, de trazar en el discurrir poético una realidad elevada, exaltada. El ya aludido casi coetáneo del 27 Emilio Orozco, expuso a su vez estos mismos hechos de una manera decidida y en palabras que cabe recordar: algunos contemporáneos de don Luis -nos hace notar- apuntaron dos caracteres fundamentales «del estilo culterano: el halago de los ojos y el halago de los oídos, esto es, valores pictóricos y valores musicales»; señala también este crítico que se trata de algo caracterizador del Barroco, «el desarrollo de todo lo aparencial. [...] Como decía Alfonso Reyes, las armas con que Góngora emprende su revolución estética «son las armas de la sensualidad» (Orozco, 1984, p. 57, palabras del epígrafe «Góngora, poeta de los sentidos»).

6. LAS CONFERENCIAS TURnbULl EN CASTELLANO (1976): «LA REALIDAD Y EL POETA» (II)

Y en fin, en La realidad y el poeta, vuelve nuestro escritor y crítico a José de Espronceda, y en tal capítulo (el VI de su obra) va estampando estas interpretaciones, a saber:

1. «Góngora es el último poeta de la edad clásica. Después [...] casi por espacio de dos siglos, puede decirse que no hay gran poesía en España. Se necesita la revolución romántica para que surja otra gran personalidad de poeta».

2. La nota tónica de la vida de Espronceda, como la de cualquier romántico, fue la de disconformidad.

3. La concepción del mundo en tanto misterio, es un impulso fuerte también de los románticos.

4. La voz «anhelo» resulta «la palabra básica del romanticismo».

5. «El nuevo hombre, el hombre romántico - estamos ante el personaje don Félix de Montemar de El estudiante de Salamanca- [...] se alza frente al misterio de la vida y de la realidad, y se encara con Dios en actitud de rebeldía satánica. Es el hombre que no quiere resignarse a sus límites, al no saber [...]. La realidad, el mundo, la vida, no entregan su misterio. O la clave de ese misterio es sencillamente la muerte. Pero la muerte final como término absoluto de la vida, y no como tránsito a otra vida superior y eterna. Es la muerte del romántico en plena rebeldía, en desesperación».

y 6) «"Que haya un cadáver más, ¿qué importa al mundo?”. Aquí vemos la queja desesperada ante la indiferencia, la dureza de la realidad. Aquí vemos que el 
hombre se siente irrevocablemente separado de ella. [...] El mundo gira alegre. Y él mientras tanto siente su corazón destrozado» (todo esto en Salinas, 2007, pp. 487-493).

El presente libro de Pedro Salinas se cierra con un párrafo en el que vuelve a llamar la atención sobre el hecho que creía inadvertido entonces, de cómo Góngora extrajo de la realidad que nos rodea otra realidad creadora e imaginativa.

$\mathrm{Al}$ comienzo del volumen («La realidad y el poeta en la poesía española»), el autor expone cómo hubiese deseado dedicar un capítulo a Jorge Guillén y su concepto de la realidad, pero que el tiempo y las circunstancias no lo habían hecho posible; recordemos no obstante cómo al hacer la reseña de «Cántico», nuestro autor tenía escrito que «la poesía de Guillén siendo tan real, es al par [...] antirrealista, y da una sensación [...] perfecta de mundo purificado, esbelto, platónico, de maravillosa selva de ideas de las cosas»; Guillén -en esta interpretación-, poetiza platónica o fenomenológicamente las ideas y las esencias de las cosas, y manifiesta su júbilo por el puro vivir y por las cosas entre las que se encuentra, visión crítica ciertamente acertada (un especialista en el 27 y en Salinas, Joaquín González Muela, ha estudiado años más tarde del deseo de don Pedro de hacerlo, La realidad y Jorge Guillén: González Muela, 1962).

\section{7. «SigNO DE LA LITERATURA ESPAÑOLA DEL SIGLO XX»}

En 1940 se fecha otra conferencia de don Pedro, cuyo contenido bien nos importa: se trata de «El signo de la literatura española del siglo XX», y en ella expone cuál es la orientación más característica, cuál la contextura de las letras artísticas castellanas en las cuatro primeras décadas de la centuria.

Con un signo -se inicia Salinas- se nos da la significación de algo, «y la significación de una cosa es lo que quiere decir, su querer decir precisamente esto y no aquello. [...] El signo del siglo XX es el signo lírico» (Salinas, 2007, 77).

Antes de entrar en ese carácter lírico de nuestras letras del Novecientos, ha de resaltarse un hecho: a esta altura de 1940 Pedro Salinas parece conocer perfectamente el Curso de lingüística general de Ferdinand de Saussure: para Saussure la lengua se halla constituida por entidades opositivas, relativas y negativas, y en efecto y según mantiene por igual Salinas, la significación es justamente «el querer decir esto y no aquello», el designarlo y así significarlo en una lengua particular concreta.

De esta manera el signo de la literatura del XX es el lírico: esta voz «lírico» significa y hace designación del carácter que el autor estima fundamental de las letras de las primeras décadas de la centuria.

Explica Pedro Salinas:

El signo del siglo XX es el signo lírico -queda visto que dice el poeta-; los autores más importantes de ese periodo adoptan una actitud de lirismo radical al tratar los temas literarios. Ese lirismo básico, esencial (lirismo no de la letra, sino del espíritu), se manifiesta en variadas formas, a veces en las menos esperadas, y él es el que vierte sobre novela, ensayo, teatro, esa ardiente tonalidad poética que percibimos en la mayoría de las obras importantes de nuestros días (Salinas, 2007, p. 77). 
Todo lector recordará con facilidad que los poemas en prosa presentes en varias novelas de Baroja; que los textos de Azorín, Ortega, Ramón Gómez de la Serna, Gabriel Miró o de Azaña; que los textos en prosa de Luis Cernuda o incluso del escritor de novela revolucionaria César Muñoz Arconada, etc., se remontan ciertamente a tal lirismo del espíritu que percibe y diagnostica Salinas, y el lector asentirá con él.

Para el crítico ciertamente ha de estimarse «la altura y densidad de la producción poética desde 1900 hasta hoy [1940]», y cómo España ha tenido en tales cuarenta años «muy altos y muchos poetas». De quienes eran contemporáneos suyos, don Pedro menciona -según era de esperar- a Unamuno, Antonio Machado y Juan Ramón Jiménez; de los coetáneos y varios de ellos contemporáneos de parte de nosotros y de gentes más jóvenes, a Federico García Lorca, Jorge Guillén y Rafael Alberti, a los cuales -dice el madrileño- «podemos ya dar como electos, por derecho propio de su naturaleza poética, para [...] la Academia de la Gran Poesía Española» (Salinas, 2007, p. 80).

Don Pedro es muy entusiasta, y más que proclamar casi exclama, en palabras memorables: «Sí, hay algo más que poetas españoles modernos: hay una poesía española moderna, rica en grados, diferencias y matices, discernible [...] por las dos notas de altura y densidad» (Ibid.).

Se trata además de una «constancia», pues tal actitud lírica de nuestras letras contemporáneas no se presenta en un posible momento de intensidad «cual suele suceder con el lirismo en la historia literaria, sino que es una constante en el curso de estos cuarenta años, manifestada en sucesivas salidas o apariciones de nuevos poetas o nuevas tendencias, que ocurren sin interrupción» (Ibid.).

Existe en la percepción de Salinas un fluir o tradición de tendencias emparentadas en el primer tercio amplio del Novecientos, con fechas de importancia hacia 1907; según don Pedro, en la «pública plenitud» del año 1928, con obras como el «Primer romancero gitano», «Cántico», y «Cal y canto» y «Sobre los ángeles» (Salinas, 2007, pp. 80-81; realmente las obras de Alberti son del 29); en fin subraya asimismo el madrileño el año 1935 -en verdad son los 1935/1936-, por los textos aparecidos entonces «La destrucción o el amor» y «La realidad y el deseo» (Ibid.). Resulta triste comprobar -digamos en adhesión al poeta- cómo al Salinas ya en el exilio a consecuencia del golpe de Estado militar y la subsiguiente guerra civil, se le van desdibujando los recuerdos y las fechas.

Por último interpreta nuestro autor en relación a este signo lírico de las letras que él analiza y postula en su crítica literaria, cómo «en un período de inestabilidad de sentimientos, de profunda conmoción de la sensibilidad, se entronizará, dueña casi absoluta, la poesía» (Salinas, 2007, p. 81).

En conclusión se trata en las letras castellanas de algo más del primer tercio del XX que «el lirismo contemporáneo medra no solo en las altas temperaturas de la poesía lírica, [...] sino en las regiones mucho menos encendidas de la novela, y, victoria final, hasta en las generalmente frías del ensayo. Toda nuestra literatura está impregnada de lirismo» (Ibid., p. 82, subrayado por nosotros).

Acabamos de aludir a una idea de nuestro crítico, la de que -lo recogemos de nuevo- «en un período de inestabilidad de sentimientos, de profunda conmoción de la sensibilidad, se entronizará, dueña casi absoluta, la poesía»; desde luego hay que rectificar en parte a Pedro Salinas, pues aunque alguna novela se hallase penetrada de lirismo no dejaba de ser novela, novela en distintos autores -autores asimismo del $27-$ 
«de avanzada». Esa «inestabilidad de sentimientos» que hace que (como se ha hecho varias veces) los críticos hablen de una trayectoria que va de la anhelada pureza poética al compromiso y a la revolución; la «profunda conmoción de la sensibilidad» ante lo ocurrido en la España del primer tercio del siglo XX; etc., apunta a unos caracteres de tales tiempos -el aludido más o menos primer tercio de siglo- que cabe ilustrar en poco más de dos palabras.

Para tal ilustración creemos que son muy sugestivas tres páginas del historiador José María Jover -otro de los hermanos menores del 27 poético y novelístico, de la generación siguiente-, que enseñan e ilustran cómo los años del reinado de Alfonso XIII a los que él se refiere más en concreto, y los años europeos que van de 1914 a 1945 (otra guerra europea de los Treinta Años), constituyen una verdadera «época de la violencia», aunque entre nosotros sea asimismo la época de los regeneracionismos, según subraya a su vez Comellas (1988, parte cuarta, pp. 295 y ss.,; el presente especialista prescinde por completo en su exposición de los hechos de cultura). Principiaba exponiendo así Jover:

La denominación [época de la violencia] es tan expresiva y tan adecuada [... que debe mantenerse] en un primer plano de la atención [,] la realidad omnipresente [...] de un clima de violencia, de menosprecio a la vida humana; de demoníaco instinto de destrucción, al servicio del cual será puesto el potencial técnico por la revolución industrial; [la realidad omnipresente] de supeditación expresa de todo impulso de caridad cristiana a unos mitos irremediablemente falsos en la trascendencia que ahora se les confiere, pero de enorme fuerza sugestiva en una sociedad de masas (Jover, 1963, p. 675-676).

La conmoción sentimental e inestable que afecta a los escritores y que se halla referida por Pedro Salinas, es sin duda esta de las sucesivas violencias glosadas por José María Jover, quien escribe en años de pleno franquismo en los que aún existía la censura previa, y ha de manifestarse con mucha prudencia para que sus páginas pudiesen ser publicadas: desde luego la supeditación que menciona del impulso de caridad cristiana a los mitos del superhombre y de la violencia, bien puede interpretarse también en tanto supeditación del impulso de la fraternidad laica proclamada por ej. por Federico García Lorca en Poeta en Nueva York, y que nosotros estimamos que resulta en él una impregnación de la ética del krausismo español.

En España -prosigue el historiador Jover- un talante colectivo de violencia impregna una triple crisis -social, política, espiritual- llamada a desembocar en la «guerra de España», la más sangrienta guerra civil de nuestra historia (1936-1939); la cual, por otra parte, servirá de pórtico a la segunda guerra mundial por los elementos extrapeninsulares en ella implicados (Ibid., p. 676).

Y señala aún en líneas inmediatas nuestro autor, con gran agudeza, cómo esa llamada por la historiografía internacional «guerra de España» (recordemos que la conocida fuera de nuestras fronteras como «guerra peninsular» es la de 1808), «viene a poner súbitamente de manifiesto un conjunto de fuerzas y de tendencias virtuales, aunque todavía no claramente explícitas, en el período [1902-1931]» (Ibid., p. 677). Se trata pues de que en el 36 salen a la superficie de manera total las tendencias y fuerzas operantes desde tiempo atrás: desde el Ochocientos se habían ido acumulando el mal modo de hacer las desamortizaciones; las tres guerras carlistas -con ironía o humor po- 
dría denominarse que la de 1936 fue la «cuarta guerra carlista»-; las guerras coloniales (las de Marruecos con tanta repercusión en la vida española de dos decenios del XX, y repercusión asimismo en la novelística); el trabajo en el campo «de sol a sol» que aún recuerdan personas que viven; el subproletariado industrial; etc.; ahora en el 36 todo resulta explícito y total, y el golpe de Estado aboca al pueblo español a una guerra sin piedad muy prolongada.

La sacudida emocional en cuanto factor actuante de estos años sobre los poetas (Pedro Salinas) -y sobre novelistas y ensayistas-, los aclara el mismo Jover haciendo referencias algunas de las cuales transcribimos (estas páginas suyas del año 63 se hallan fuera del mercado, pues incluso su propio autor las refundió, pero interesan por la fecha relativamente cercana a Salinas):

a) Se acentúa - no olvidemos que el autor trata conjuntamente del reinado de Alfonso XIII, o sea, más o menos del periodo de la primera vanguardia o vanguardia histórica- «una crisis social de compleja motivación, pero en la cual es preciso destacar tres factores: el mantenimiento de unas estructuras campesinas anacrónicas; la inercia de las clases dirigentes, y el recurso a la violencia por parte de las fuerzas sociales enfrentadas» (Jover, 1963, p. 677), violencias de la Semana Trágica o del pistolerismo de la patronal barcelonesa amparada por el gobernador civil (y luego ministro de Orden Público de tan triste recuerdo) Severiano Martínez Anido, etc. Vicens en concreto habló del «martirio de Cataluña» entre 1918 y 1923 (Vicens, 2012, p. 182).

b) Está presente una crisis política que se manifiesta «en el plano de la opinión pública y de la cohesión moral de los españoles, en una desintegración política de la sociedad española, fragmentada en grupos cuyas relaciones aparecen presididas por una creciente intransigencia; por un endurecimiento separatista más orientado al cumplimiento íntegro del propio respectivo programa, que a salvaguardar la convivencia nacional» (Ibid.).

c) Asistimos -y es lo que en una mínima parte estamos analizando en las presentes páginas nuestras- a «un extraordinario apogeo cultural [...]; España aporta en este primer tercio de siglo a la cultura de Occidente algunos nombres y algunas creaciones de valor universal. Ahora bien, si tanto en el plano de la creación intelectual como en el de la creación estética se llega a niveles no alcanzados desde el Siglo de Oro, en el plano de los valores religiosos -fe, caridad fraterna, comprensión del adversario sin perjuicio de la firmeza de las propias convicciones-, la situación es menos satisfactoria; el contragolpe de la guerra europea de 1914-18, la oleada de inmoralidad que comporta toda posguerra, la crisis moral subsiguiente a la «gran crisis» de 1929, no harán más que exacerbar en la Península una situación. [...] Una crisis espiritual discurre pues paralelamente al extraordinario apogeo cultural» (Ibid., pp. 677-678).

Esta crisis impregnará según empezó a apuntar Pedro Salinas la lírica y la trayectoria de la lírica, y también los demás géneros literarios, en particular el ensayo, y por igual en cierta medida la novela. 


\section{REFERENCIAS BIBLIOGRÁFICAS COMENTADAS}

Archivo de la Palabra. Voces de la Edad de Plata: Publicaciones de la Residencia de Estudiantes, Madrid, 1998. Precioso testimonio de época, muy emocionante.

Barrera López, José María (1991): Pedro Salinas en la Universidad literaria de Sevilla, Universidad de Sevilla. Este libro y el siguiente artículo que mencionamos resultan de consulta necesaria para conocer la labor del Pedro Salinas catedrático en la ciudad hispalense, antes de ir al «Centro de Estudios Históricos» y al exilio ya para siempre. El texto satisface una curiosidad filológica no banal.

- (1992): «Los cursos de Pedro Salinas», en Pedro Salinas en su centenario (1891-1991), Universidad de Sevilla, pp. 103-124.

Castro, Américo (1925): El pensamiento de Cervantes, Madrid, Centro de Estudios Históricos de la Junta para Ampliación de Estudios. Obra de relieve entre las publicaciones del autor -que se dedicó menos a la materia de su cátedra, la Historia del idioma español-, y entre las de la escuela pidalina-. Ha de verse inexcusablemente según el texto de esta primera edición.

Catalán, Diego (1974): Lingüística Íbero-Románica, Madrid, Gredos. Revisión de cien años de estudios españoles o foráneos, de análisis diacrónico, dialectal, toponímico, etc. Enjuiciamientos imparciales.

Comellas, José Luis (1988): Historia de España Contemporánea, Madrid, Rialp. Manual útil en ocasiones, escrito desde el punto de vista conservador que caracteriza al autor.

Ferrater Mora, José (1979): Diccionario de Filosofía, Madrid, Alianza Editorial, sexta edición, cuatro volúmenes. Obra impar, debida al esfuerzo de una sola persona, y de gran utilidad. Ferrater era algo menor que el 27 , aunque no mucho.

González Muela, Joaquín (1962): La realidad y Jorge Guillén, Madrid, Ínsula. Otro texto dedicado al 27 por su autor, un filólogo estimable a medio camino entre la lingüística y los estudios literarios. Una segunda edición que preparaba para Espasa no llegó a ver la luz.

Jover Zamora, José María (1963): «Edad Contemporánea», en la obra de Antonio Ubieto, Juan Reglá y J. M. Jover Introduducción a la Historia de España, Barcelona, Teide, pp. 417-765. Exposición vigente en lo fundamental, de gran sensibilidad hacia aspectos que suelen descuidarse: los culturales, las relaciones internacionales,... Retocada y ampliada en ediciones sucesivas del libro, y refundida luego con la colaboración de su discípula G. Gómez-Ferrer.

Lapesa, Rafael, ed. (1947): Poetas del siglo XVI, Barcelona, Rauter. Libro elemental, pero hecho con seriedad e instructivo.

- (1948): La trayectoria poética de Garcilaso, Ed. Revista de Occidente. Texto clásico que sirvió como trabajo de firma de la cátedra de «Gramática General y Crítica Literaria» que el autor pensaba hacer. Conserva toda su vigencia, y de hecho arranca del gusto por el toledano del «Centro de Estudios Históricos»: una época de la lengua castellana del XVI está llamada por Menéndez Pidal «Período de Garcilaso».

- (1967): De la Edad Media a nuestros días. Estudios de Historia literaria, Madrid, Gredos. Recopilación de artículos, alguno -según es inevitable en lo humano- más desvaído, pero varios de ellos muy instructivos.

L[óPez] Aranguren, José Luis (1970) [1966]: Moral y sociedad. Introducción a la moral social española del siglo XIX, Madrid, Editorial Cuadernos para el Diálogo. Bello estudio que es lástima no lo prolongase el autor hasta el siglo XX, si bien es verdad que su publicación coincidió con su expulsión universitaria y exilio temporal.

Maravall, José Antonio (1967): Teoría del saber histórico, Madrid, tercera ed., Eds. de la Revista de Occidente. Obra señera en su momento y en su género, conserva toda vigencia intelectual más de medio siglo después de su primera aparición. Ha de manejarse esta 
tercera edición, que añade no mucho, pero sí de importancia. Planteamiento brillante que nos resulta útil para entender las nociones de época histórica (Barroco, etc.), y de literatura como sistema.

- (1984): Estudios de Historia del pensamiento español. Segunda serie. La época del Renacimiento, Madrid, Eds. Cultura Hispánica. Aportación española fundamental y extensa al concepto de «Renacimiento»; no parece haber otra análoga, aunque de los libros del autor es de los menos mencionados y -según eso- utilizados.

MenÉndez PIDAL, Ramón (1933): «El lenguaje del siglo XVI», Cruz y Raya, 6, 15 de Septiembre, pp. 7-63. Primera manifestación de una Historia de la lengua española que entraba en los proyectos del autor. En la traza de su maestro Menéndez Pelayo, Pidal avalora la lengua clara e inmediatamente inteligible del Quinientos, y llevado por su castellanismo y su nacionalismo, exalta el momento -1555-1585- en que él interpreta que la lengua hablada se hace lengua escrita y literaria (los cambios consonánticos que se generalizan; Santa Teresa; etc.). El presente artículo subdivide la centuria en períodos menores de hacia un tercio de signo, algo que abandonó el autor cuando volvió al asunto -en páginas de redacción diferente- en la Historia de la lengua española editada póstumamente por su albacea Diego Catalán. Trabajo por tanto no superado -sino distinto- del que suponen las páginas correspondientes de la Historia... que acabamos de mencionar. De lectura necesaria para el asunto.

- (1957a): Poesía juglaresca y orígenes de las literaturas románicas, Madrid, sexta ed., Instituto de Estudios Políticos. Edición definitiva de esta obra de historia literaria y cultural, que añade ahora consideraciones teóricas.

- (1957b): España y su historia, Madrid, Eds. Minotauro, I y II. Agrupación orgánica de artículos y partes de libros, de manera que se perfile una interpretación del pasado español. Están reunidas investigaciones lingüísticas, literarias e históricas, y ello como muestra de la concepción filológica totalizadora que mantenía y enseñaba el autor.

- (2005): Historia de la lengua española, Madrid, Fundación Ramón Menéndez Pidal y Real Academia Española, I y II. Obra póstuma, de primer interés para la materia, que se ocupa lo mismo del hablar común que del lenguaje literario. Imprescindible para todo filólogo del español, ha quedado no obstante un tanto inadvertida; recibió reseñas periodísticas algunas de ellas con desenfoques.

Moreno Villa, José (1976): Los autores como actores y otros intereses literarios de acá y de allá, Madrid, Fondo de Cultura Económica, reimpresión. Preciosas evocaciones y estudios literarios del autor. Volumen testimonial y documentalmente necesario.

Newman, Jean Cross (2004): Pedro Salinas y su circunstancia, Madrid, Páginas de Espuma. Bella obra, informada y de la que el lector desprende acaso -así nos ha ocurrido a nosotros-, la tristeza de la pronta muerte del biografiado, el cual aparece en alguna foto con el semblante de la grave enfermedad. Los primeros años de don Pedro transcurrieron además en un bello paisaje urbano que aquí se referencia: el de las calles Toledo, Don Pedro, etc., de Madrid.

Orozco, Emilio (1984), Introducción a Góngora, Barcelona, Crítica, 1984. Reedición bastante ampliada con nuevas anotaciones de una obra clásica. Interpretaciones socio-históricas un tanto idealizadas en ocasiones.

Orozco DíAz, Emilio (2004): Grandes poetas renacentistas, Málaga, Universidad. Reunión póstuma de capítulos y artículos de un conocedor sensible de las letras españolas, ligeramente más joven que los del 27 pero que ya alcanzó a vivir con consciencia parte de los años veinte y los treinta, y compartió los intereses poéticos y a la vez artístico-plásticos de la Vanguardia. De interés para la materia que aborda: Garcilaso, Herrera, San Juan, Fray Luis, etc

Poema de Mío Cid. Versión de Pedro Salinas (1975) [1926]: octava edición, Madrid, Eds. de la Revista de Occidente. Una de las mejores versiones -si no la mejor- con que contamos del texto medieval de hacia 1200 . 
Salinas [Serrano], Pedro (2007): Obras Completas. II. Ensayos completos, edición al cuidado de Enric Bou, Madrid, Cátedra, 1534 págs. Resulta ahora una publicación imprescindible por su gran utilidad; debe tenerse siempre a la vista. El tomo recoge los escritos crítico-literarios y de ensayo del autor. Es un tomo que -según decimos- no hace falta encarecer.

Vicens Vives, Jaime -con L. Pericot y A. del Castillo- (1945/1960): Polis. Historia universal, Barcelona, Ed. Vicens-Vives. Exposición obligadamente elemental pero con las garantías que da su autor.

VicENS Vives, Jaume (2012): España contemporánea (1814-1953), Barcelona, El Acantilado. Reconstrucción de un texto inédito en cuanto tal, aunque conocido en parte: la España de Franco no hubiera dejado publicarlo tal como ahora lo vemos*.

\footnotetext{
* Las presentes Notas son para la soprano Beatriz Díaz Gónzalez y para la prof. ${ }^{a}$ M. ${ }^{a}$ Jesús Viguera.
} 